\title{
A Mini Review on Doped Nickel-Based Electrocatalysts for Hydrogen Evolution Reaction
}

\author{
Yilin Deng ${ }^{1,2}$, Wei Lai ${ }^{1}$ and Bin $\mathrm{Xu}^{2, *}$ \\ 1 Institute for Energy Research, Jiangsu University, 301 Xuefu Road, Zhenjiang 212013, China; \\ yldeng@ujs.edu.cn (Y.D.); 2221912026@stmail.ujs.edu.cn (W.L.) \\ 2 Research Center of Fluid Machinery Engineering and Technology, Jiangsu University, 301 Xuefu Road, \\ Zhenjiang 212013, China \\ * Correspondence: norkistar@ujs.edu.cn; Tel.: +86-1358-400-3613
}

Received: 22 July 2020; Accepted: 3 September 2020; Published: 7 September 2020

\begin{abstract}
The energy crisis and environmental pollution have attracted much attention and have promoted researches on clean and sustainable hydrogen energy resources. With the help of highly active and stable transition metal nickel-based catalysts, the production of hydrogen from water electrolysis from electrolyzed water has become an inexpensive and efficient strategy for generating hydrogen energy. In recent years, heteroatom doping has been found to be an effective strategy to improve the electrocatalytic hydrogen evolution reaction (HER) performances of nickel-based catalysts in acidic, neutral, and alkaline media. This review will highlight many recent works of inexpensive and readily available heteroatom-doped nickel-based HER catalysts. The evaluation methods for the performances of HER catalyst will be briefly described, and the role of heteroatom doping and its application in nickel-based catalyst will be summarized. This article will also point out some heteroatom doping strategies, which may provide references and inspire the design of other catalysts with dopants.
\end{abstract}

Keywords: nickel-based catalysts; heteroatom doping; electrochemical hydrogen evolution reaction

\section{Introduction}

As the pace of industrialization accelerates, non-renewable energy resources like fossil fuels are continuously consumed and their reserves are gradually reduced. Excessive consumption of fossil fuels is also causing the problem of continuous deterioration of the natural environment. The search for new sustainable energy sources has become a major concern in many countries [1]. In the past few decades, energy resources such as wind, solar, hydroelectric power, and hydrogen, have been regarded as sustainable and environmentally friendly alternatives to fossil fuels [2]. Hydrogen is among the most attractive energy sources for sustainable development owning to its high energy density. In addition, the combustion product of hydrogen, which is water only, is pollution-free.

Nowadays, $\mathrm{H}_{2}$ mainly comes from the steam methane reforming of natural gas, which converts methane and water steam into carbon monoxide and hydrogen. However, this process has low energy efficiency, high cost, and produces carbon-containing residues that affect the purity of hydrogen and pollute the environment [3]. Another hydrogen production technology is the use of electricity to electrolyze water so as to produce hydrogen. Hydrogen production through water splitting using solar-generated electricity has been considered as an efficient and clean way and has attracted much attention [4]. Water electrolysis consists two half reactions: the hydrogen evolution reaction (HER) at the cathode, and the oxygen evolution reaction (OER) at the anode [5]. The cathodic hydrogen evolution process involves two electronic transfers, and the pathways have been proposed as follows: [6]. 
(1) Volmer step:

$$
\begin{aligned}
& \mathrm{H}_{3} \mathrm{O}^{+} \text {(aq) }+\mathrm{e}^{-} \rightarrow \mathrm{H}^{*}+\mathrm{H}_{2} \mathrm{O}(\mathrm{l}) \text { (acidic) } \\
& \mathrm{H}_{2} \mathrm{O}(\mathrm{l})+\mathrm{e}^{-} \rightarrow \mathrm{H}^{*}+\mathrm{OH}^{-} \text {(aq) (alkaline and neutral) }
\end{aligned}
$$

(2) Heyrovsky step:

$$
\begin{aligned}
& \mathrm{H}^{*}+\mathrm{H}_{3} \mathrm{O}^{+}(\mathrm{aq})+\mathrm{e}^{-} \rightarrow \mathrm{H}_{2}(\mathrm{~g})+\mathrm{H}_{2} \mathrm{O}(\mathrm{l}) \text { (acidic) } \\
& \mathrm{H}^{*}+\mathrm{H}_{2} \mathrm{O}(\mathrm{l})+\mathrm{e}^{-} \rightarrow \mathrm{H}_{2}(\mathrm{~g})+\mathrm{OH}^{-}(\mathrm{aq}) \text { (alkaline and neutral) }
\end{aligned}
$$

or Tafel step:

$\mathrm{H}^{*}+\mathrm{H}^{*} \rightarrow \mathrm{H}_{2}$ (g) (acidic, alkaline, and neutral)

$\left(\mathrm{H}^{*}\right.$ : adsorbed hydrogen at the active site of the catalyst)

At present, the most effective electrocatalysts for HER are platinum-based materials. However, the low abundance and high cost of platinum has limited its application in industry [7]. Therefore, the development of catalysts with low cost, large reserves, good stability, and high catalytic activity has become a key step in the industrial production of $\mathrm{H}_{2}$ from water electrolysis. As a result, those inexpensive and readily available transition metal ( $\mathrm{Mo}, \mathrm{Fe}, \mathrm{Co}$, and $\mathrm{Ni}$ )-based electrocatalysts have been massively developed [8-11].

Nickel-based catalysts with high stability and activity have been widely concerned for $\mathrm{H}_{2}$-evolving reaction [12]. Various types of nickel-based catalysts have been continuously developed, such as nickel oxides, hydroxides, phosphides, sulfides, nitrides, alloys, and so on [13-18]. The catalytic performances of these nickel-based catalysts can be further improved through fine surface design, elemental doping, and addition of carbon materials [19]. Studies have shown that doping or alloying of those catalysts that have been developed is an effective strategy to improve their performances [20]. Doping with other elements, can induce the formation of more active sites and new active centers [21,22]. In addition, appropriate elemental doping can also improve the intrinsic activity of the catalyst by increasing its conductivity and changing its electronic structure [23,24].

Although elemental doping has been widely explored and considered as an effective strategy to enhance the HER performance of the nickel-based catalysts, there still exist difficulties in controlling the type, amount, and dispersion of the dopants [25]. Therefore, this article summarizes and discusses recent progresses made in the design and manufacture of doped Ni-catalysts, hoping to deepen the understanding of the doping mechanism and provide reference for the design and manufacture of other doped transition metal-based catalysts.

In this review, a brief summarization of the evaluation methods for electrocatalysts is provided first. Next, we summarize the recent progresses made in the design and manufacture of doped nickel-based catalysts. The role of dopants and their applications in nickel-based HER catalysts are discussed in detail. We hope this work can deepen the understanding of the doping mechanism, so as to provide some insights into resolving the difficulty of controlling the type, quantity, and dispersion of the dopants. Finally, by understanding the correlation between the dopants and the HER activity of the Ni-based catalysts, we expect to provide some perspective on the future research of high-performance doped catalysts.

\section{Evaluation Approaches of HER Electrocatalysts}

\subsection{Overpotential}

Under standard conditions, the $\mathrm{H}_{2}$-evolving potential is zero. However, in the practical HER processes, there exist kinetic barriers due to the activation energy required for the reaction [26]. The difference between the actual reaction potential and the equilibrium potential is defined as the overpotential ( $\eta$ ) of HER. Overpotential is considered as one of the most important values for evaluating water-splitting catalysts, because a large reaction overpotential will result in low energy conversion efficiency. In general, the overpotential at a current density of $10 \mathrm{~mA} / \mathrm{cm}^{2}$ is the benchmark for evaluating catalyst performance [27]. For those electrodes with high catalyst loadings, the reaction 
potentials at 50 and $100 \mathrm{~mA} / \mathrm{cm}^{2}$ current densities can also be considered as important criteria for evaluating catalysts in practical applications.

\subsection{Tafel Slope and Exchange Current Density}

The Tafel slope is a significant parameter to evaluate the inherent HER activity of a catalyst [28]. A smaller Tafel slope suggests that a lower overpotential is required to increase the current density by the same amount, which means a more rapid charge-transfer kinetic [19]. The most common method for obtaining Tafel slope value is by taking the logarithm of the absolute value of the current density to replot the polarization curve (potential versus $\log \mid$ current density|) and fitting the linear region to the Tafel equation $\eta=b \log \left(\mathrm{j} / \mathrm{j}_{0}\right)$, where $\eta$ is the overpotential, $\mathrm{j}$ is the current density, $\mathrm{j}_{0}$ is the exchange current density and $b$ is the Tafel slope [19]. Alternatively, Hu and his colleagues calculated the slope of the linear fitting plots of log charge-transfer resistance $\left(R_{c t}\right)$ vs. overpotential based on the impedance data obtained through electrochemical impedance spectroscopy to acquire the Tafel slope [29]. The Tafel slope calculated by this method, in contrast to that obtained from voltammetry data, is not influenced by catalyst resistances, and therefore can purely reflect the charge-transfer kinetics.

The exchange current density $\left(\mathrm{j}_{0}\right)$ of the reaction is the current density at the equilibrium potential, where the cathode current is equal to the anode current. It can be obtained by extrapolating the linear part of the Tafel plot to intersect with the $X$ axis [19]. The exchange current density can also reveal the inherent activity of a catalyst. A large exchange current density indicates that only a small driving force is required for the evolution of the reaction.

\subsection{Stability}

Stability is an important evaluation criterion for HER electrocatalysts. There exist two major approaches for stability tests: repeated cyclic voltammetry $(\mathrm{CV})$ or linear scanning voltammetry (LSV) and constant current or constant potential electrolysis. Stability of a catalyst can be evaluated by comparing its polarization curves before and after continuous CV measurements (typically $500-10,000$ times) $[19,26,30]$. If the polarization curve after the cycles coincides with the original polarization curve or shows only small offset (e.g., less than $10 \%$ deviation), the catalyst is of good stability. Similarly, when evaluating the stability by constant current or constant potential electrolysis, if the working potential or working current of the catalyst only shows a small $(\leq 10 \%)$ change at an applied constant current density or constant potential after a duration of at least $10 \mathrm{~h}$, it indicates that the catalyst is of good stability.

\subsection{Electrochemical Impedance Spectroscopy}

The HER kinetics and the reactions at the interface of the electrode/electrolyte could be probed through electrochemical impedance spectroscopy (EIS). The charge-transfer resistance $\left(R_{c t}\right)$ value, obtained from the diameter of the semicircle in the high frequency zone of the EIS Nyquist plot, reflects the interface charge-transfer rate of the electrode. $R_{c t}$ is mainly dependent on the intrinsic properties of the catalyst material; hence, a small $R_{c t}$ value indicates a fast reaction rate [26,31]. In addition, the semicircle in the low frequency region represents the adsorption resistance $\left(R_{a d}\right)$ that originates from the adsorption of oxidized species on the electrode surface. $R_{a d}$ reflects the onset potential of HER, therefore a small $R_{a d}$ indicates an early HER onset [31].

\subsection{Free Energy of Hydrogen Adsorption}

Free energy of hydrogen adsorption $\left(\Delta \mathrm{G}_{\mathrm{H}^{*}}\right)$, which can be obtained via density functional theory (DFT) calculations, is also one of the key parameters to estimate the HER activity of a catalyst. In general, a good HER electrocatalyst should have a hydrogen bonding energy that is neither too weak nor too strong [32]. Weak adsorption leads to difficulty in combining protons with the electrocatalyst, while strong adsorption of $\mathrm{H}^{*}$ leads to its difficulty in the desorption from the catalyst surface. The free energy of hydrogen bonding should be close to 0 for a good HER electrocatalyst [33]. 


\section{Heteroatom-Doped Nickel-Based HER Electrocatalysts}

\subsection{Noble Metal Doping}

Nickel-based oxides, hydroxides, phosphides, sulfides, etc., have been concerned for HER catalysis [34-38]. Among them, $\mathrm{Ni}(\mathrm{OH})_{2}$ has been extensively studied for its excellent durability and superior water adsorption capacity. However, $\mathrm{Ni}(\mathrm{OH})_{2}$ material was not considered as an efficient HER catalyst because of its low intrinsic activity and excessively high free energy of hydrogen adsorption [39]. Wang et al., through Ru doping by a hydrothermal method, promoted the HER activity of $\mathrm{Ni}(\mathrm{OH})_{2}$ in alkaline electrolyte [40]. The incorporation of $\mathrm{Ru}^{3+}(\mathrm{Ru} / \mathrm{Ni}$ atomic ratio: $\sim 0.22)$ greatly changed the surface morphology of the $\mathrm{Ni}(\mathrm{OH})_{2}$ deposited on Ti mesh $\left(\mathrm{Ru}\right.$ doped $\left.\mathrm{Ni}(\mathrm{OH})_{2} / \mathrm{TM}-0.2\right)$, though some small sheets still existed on the $\mathrm{Ru}$-doped $\mathrm{Ni}(\mathrm{OH})_{2}$ surface (Figure $\left.1 \mathrm{~A}, \mathrm{~B}\right)$. The overpotential of this $\mathrm{Ru}$-doped $\mathrm{Ni}(\mathrm{OH})_{2}$ was decreased to $135 \mathrm{mV}$ at a current density of $10 \mathrm{~mA} / \mathrm{cm}^{2}$ while the overpotential of $\mathrm{Ni}(\mathrm{OH})_{2}$ material was $>210 \mathrm{mV}$ (Figure 1C). The enhanced HER activity could be attributed to the accelerated charge transfer rate, increased electrochemically reactive surface area, and appropriate $\mathrm{Ru}-\mathrm{H}$ bonding strength on $\mathrm{Ru}$ sites. The Ni atoms were more positively charged due to Ru doping, which reduced the water dissociation barrier, and thus promoted the Volmer step (Figure 1D). In addition, the introduction of $\mathrm{Ru}$ dopants into $\mathrm{Ni}(\mathrm{OH})_{2}$ increased the electrochemical active surface area (ECSA) of the catalyst, leading to an increased number of reactive sites exposed. Finally, due to the appropriate bonding strength between $\mathrm{Ru}$ and $\mathrm{H}, \mathrm{Ru}$ sites were suitable active centers for $\mathrm{H}$ intermediate bonding and the following $\mathrm{H}_{2}$ formation and dissociation processes.
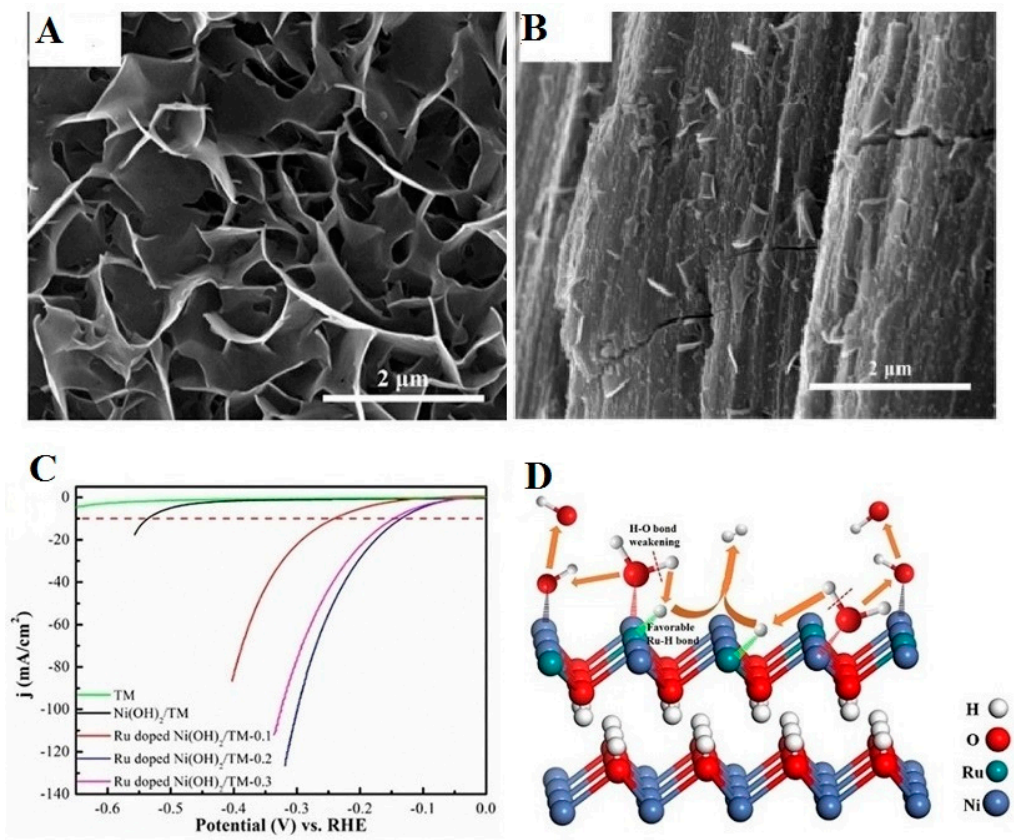

Figure 1. (A) SEM image of $\mathrm{Ni}(\mathrm{OH})_{2} / \mathrm{TM}$. (B) SEM image of Ru-doped $\mathrm{Ni}(\mathrm{OH})_{2} / \mathrm{TM}-0.2$. (C) Polarization curves of TM, Ni(OH) 2 /TM, Ru doped $\mathrm{Ni}(\mathrm{OH})_{2} / \mathrm{TM}-0.1$, Ru doped $\mathrm{Ni}(\mathrm{OH})_{2} / \mathrm{TM}-0.2$, and Ru doped $\mathrm{Ni}(\mathrm{OH})_{2} / \mathrm{TM}-0.3$. (D) The proposed synergistic effect in $\mathrm{Ru}$ doped $\mathrm{Ni}(\mathrm{OH})_{2} / \mathrm{TM}$ for HER (reprinted with permission from ref [40]. Copyright (C) 2019, Elsevier).

He et al., employed a nickel-vacancy-mediated synthesis strategy to accomplish the synthesis of $\mathrm{Ni}_{5} \mathrm{P}_{4}$ nanoparticles containing $3.83 \mathrm{wt} \%$ single-atom $\mathrm{Ru}\left(\mathrm{Ni}_{5} \mathrm{P}_{4}-\mathrm{Ru}\right)$ [41]. The $\mathrm{Ru}$ sites were first incorporated into a nickel-vacancy-rich nickel hydroxide, with the nickel vacancies stabilizing the $\mathrm{Ru}^{3+}$. A subsequent phosphorization treatment further transformed the material to $\mathrm{Ni}_{5} \mathrm{P}_{4}-\mathrm{Ru}_{\text {, }}$ which incorporated single-atom $\mathrm{Ru}^{0}$ dopants. The $\mathrm{Ni}_{5} \mathrm{P}_{4}-\mathrm{Ru}$ exhibited a low initial potential of $17 \mathrm{mV}$ vs. RHE and a small overpotential of $54 \mathrm{mV}$ at a current density of $10 \mathrm{~mA} / \mathrm{cm}^{2}$ (Figure 2). Spin-polarized 
DFT method was employed to perform calculations. The Perdew-Burke-Ernzerhof (PBE) functional of generalized gradient approximation (GGA) was used as the electron exchange-correlation potential. Spectral analysis combined with DFT calculations revealed that Ru doping polarized the local structure of $\mathrm{Ni}_{5} \mathrm{P}_{4}$, lowered the hydrolysis barrier, and optimized the free energy for $\mathrm{H}$ adsorption. Hence, appropriate integrated structural adjustment and active site incorporation could be the strategy to achieve efficient electrocatalysts.
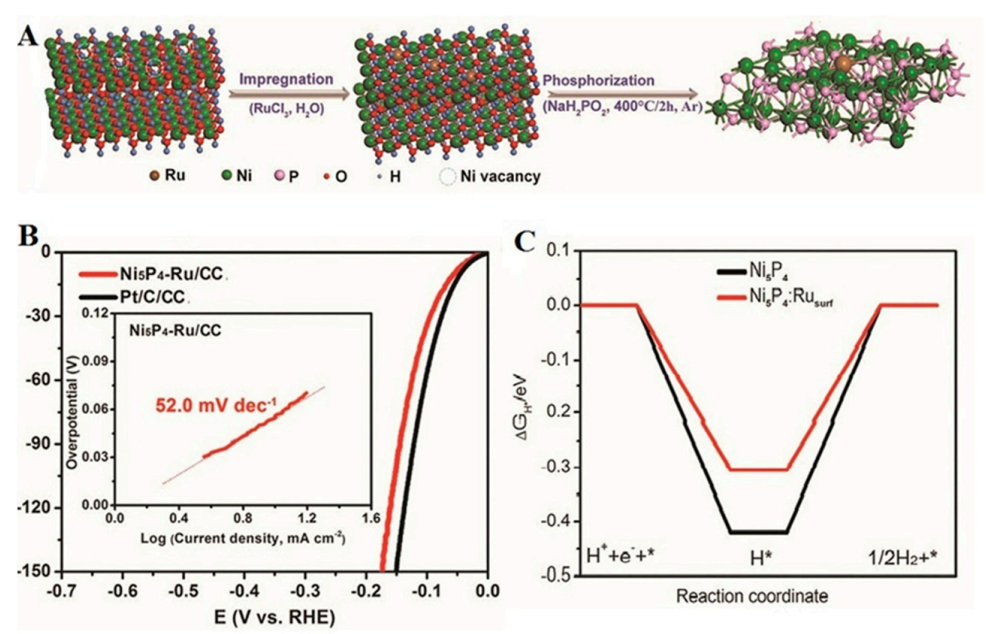

Figure 2. (A) Schematic illustration of the fabrication of $\mathrm{Ni}_{5} \mathrm{P}_{4}-\mathrm{Ru}$. (B) Hydrogen evolution reaction (HER) linear scanning voltammetry (LSV) curves for the $\mathrm{Ni}_{5} \mathrm{P}_{4}-\mathrm{Ru}$ and $\mathrm{Pt} / \mathrm{C}$ loaded on carbon cloth (CC). The inserted figure showed the Tafel plot of $\mathrm{Ni}_{5} \mathrm{P}_{4}-\mathrm{Ru} / \mathrm{CC}$. (C) Free energy of hydrogen adsorption on $\mathrm{Ni}_{5} \mathrm{P}_{4}$ and $\mathrm{Ni}_{5} \mathrm{P}_{4}-\mathrm{Ru}$ (reprinted with permission from ref [41]. Copyright @ 2020, John Wiley and Sons).

Chen et al., employed Co leaf-like zeolitic imidazolate framework (Co ZIF-L/NF) as precursor to synthesize the Ru-doped 3D flower-like bimetallic phosphide on nickel foam (Ru-NiCoP/NF), through $\mathrm{Ru}^{3+}$ etching and low-temperature phosphorization strategy [42]. This Ru-NiCoP/NF (quantitative percentage of Ru: 0.42 at\%) exhibited an overpotential of only $44 \mathrm{mV}$ at a $\mathrm{H}_{2}$-evolving current density of $10 \mathrm{~mA} / \mathrm{cm}^{2}$ and a small Tafel slope of $45.4 \mathrm{mV} / \mathrm{dec}$ in $1.0 \mathrm{M} \mathrm{KOH}$. It was proposed that $\mathrm{Ru}$ dopants in the $\mathrm{Ni}$ sites of $\mathrm{NiCoP}$, which served as the active sites for $\mathrm{H}_{2}$ evolution, could optimize the Gibbs free energy of hydrogen adsorption $(-0.034 \mathrm{eV})$ and increase the charge transfer rate; therefore, promoting the HER performance of the catalyst.

Recently, Li et al., reported an Ir-doped NiV layered double hydroxide (IrNiV-LDH) catalyst, which was synthesized via a one-step hydrothermal method, for electrochemical water splitting [22]. It was found that in pristine NiV-LDH without Ir dopants, $\mathrm{V}$ ions were in $+3,+4$, and +5 valence states. The bridging oxygen atom between Ni and $\mathrm{V}$ was the active center of HER. The $\Delta \mathrm{G}_{\mathrm{H}^{*}}$ of bridge oxygen was appropriately modified by the vanadium dopants, making the bridge oxygen atoms HER-active centers. In further research work, iridium doping was conducted to the NiV-LDH to further enhance the performance of the catalyst. DFT $+\mathrm{U}$ (Hubbard-U correction) method was also employed in this study to illustrate the effect of Ir doping. After a nickel atom was replaced by an $\mathrm{Ir}^{3+}$, the ratio of $\mathrm{V}^{3+}$ increased significantly, indicating the Ir dopants introduced a decrease in the valence state of the $\mathrm{V}$ ions. The charge density at the bridge oxygen atom between the vanadium and the Ir decreased significantly, which reduced the excessively strong adsorption of the $\mathrm{H}$ intermediates; therefore, enhancing the HER performance of the catalyst. Moreover, the Ir dopants exhibited lower energy barrier for water dissociation compared to the $\mathrm{V}$ sites; hence, serving as the new reactive centers for the Volmer step in alkaline solutions. Therefore, Ir doping in NiV LDH achieved the synergistic HER catalysis at the double active centers of the Ir atom and the bridge oxygen atom. As a result, with Ir dopants in $\mathrm{NiV} \mathrm{LDH}\left(\mathrm{Ni}_{0.57} \mathrm{~V}_{0.29} \mathrm{Ir}_{0.14}-\mathrm{LDH}\right)$, a small overpotential of only $41 \mathrm{mV}$ was achieved at a $\mathrm{H}_{2}$-evolving current density of $10 \mathrm{~mA} / \mathrm{cm}^{2}$ on the catalyst (Figure 3). 

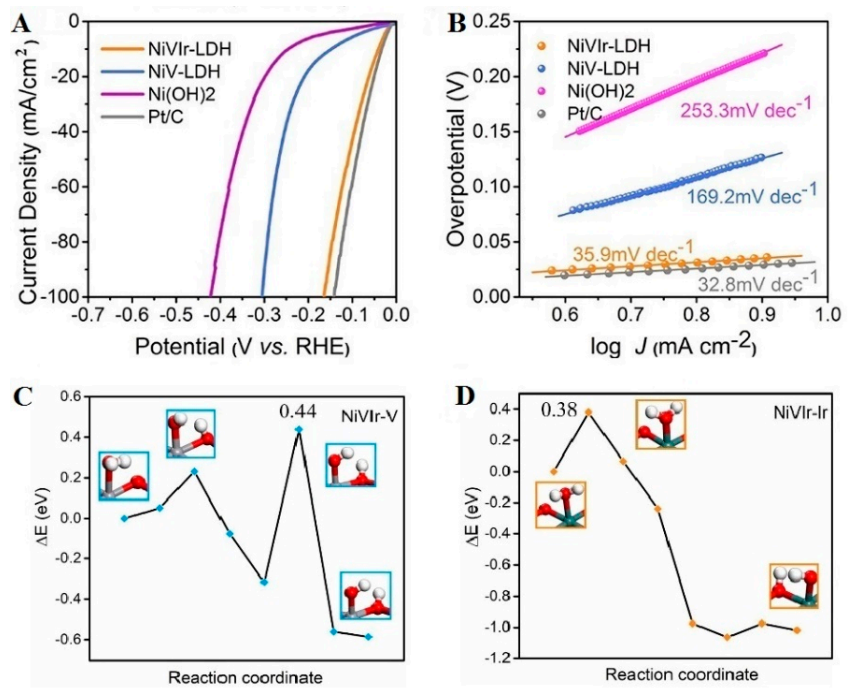

Figure 3. (A) Polarization curves and (B) Tafel slopes of $\mathrm{Ni}(\mathrm{OH})_{2}, \mathrm{NiV}-\mathrm{LDH}, \mathrm{NiVIr}-\mathrm{LDH}$, and Pt/C. Water dissociation barriers on (C) V and (D) Ir sites in NiVIr (reprinted with permission from ref [22]. Copyright (C) 2019, American Chemical Society).

Fan et al., used a simple low-temperature solvothermal and spontaneous galvanic displacement reaction (Ir ions replacing NiCo in the NiCo layered double hydroxide) in atmosphere to fabricate Ir-doped NiCo LDH catalyst (Ir content: $3.4 \mathrm{wt} \%$ ) [43]. The Ir-doped NiCo LDH exhibited an overpotential of $21 \mathrm{mV}$ at a $\mathrm{H}_{2}$-evolving current density of $10 \mathrm{~mA} / \mathrm{cm}^{2}$ and a low Tafel slope of $33.2 \mathrm{mV} / \mathrm{dec}$ in $1.0 \mathrm{M} \mathrm{KOH}$. The X-ray photoelectron spectroscopy (XPS) results showed an increased valence state of the iridium dopants compared to the initial $\mathrm{Ir}^{3+}$ reactant. In addition, the binding energies of $\mathrm{Ni} 2 \mathrm{p}$ and $\mathrm{Co} 2 \mathrm{p}$ shifted to higher and lower values, respectively. These results indicated that Ir doping altered the electronic structure of the NiCo LDH. Moreover, Ir-doped NiCo LDH showed a significantly larger electrochemical active surface area and higher conductivity compared to the NiCo LDH, contributing to the excellent HER performance of the catalyst. A summary of the HER performances of the representative doped Ni-based catalysts under different conditions is presented in Table 1.

Table 1. HER performances of various doped nickel-based electrocatalysts.

\begin{tabular}{|c|c|c|c|c|}
\hline Catalyst & Electrolyte & Overpotential (mV) $\eta_{10}$ & Tafel Slope (mV/dec) & Ref. \\
\hline Ru doped $\mathrm{Ni}(\mathrm{OH})_{2} / \mathrm{TM}-0.2^{1}$ & $1.0 \mathrm{M} \mathrm{KOH}$ & 135 & 63.7 & [40] \\
\hline $\mathrm{Ni}_{5} \mathrm{P}_{4}-\mathrm{Ru}$ & $1.0 \mathrm{M} \mathrm{KOH}$ & 54 & 52.0 & [41] \\
\hline $\mathrm{Ru}-\mathrm{NiCoP} / \mathrm{NF}^{2}$ & $1.0 \mathrm{M} \mathrm{KOH}$ & 44 & 45.4 & [42] \\
\hline $\mathrm{Ni}_{0.57} \mathrm{~V}_{0.29} \mathrm{Ir}_{0.14}-\mathrm{LDH}$ & $1.0 \mathrm{M} \mathrm{KOH}$ & 41 & 35.9 & [22] \\
\hline Ir-doped NiCo LDH & $1.0 \mathrm{M} \mathrm{KOH}$ & 21 & 35.0 & [43] \\
\hline \multirow{2}{*}{$\mathrm{Mo}-\mathrm{Ni}_{2} \mathrm{P}$} & $1.0 \mathrm{M} \mathrm{KOH}$ & 81 & 53.4 & [44] \\
\hline & $1.0 \mathrm{M} \mathrm{KOH}$ & 103 & 76.6 & \\
\hline \multirow{2}{*}{$\left(\mathrm{Fe}_{0.048} \mathrm{Ni}_{0.952}\right)_{2} \mathrm{P} / \mathrm{NF}$} & 1.0 M PBS & 90 & 82.7 & [45] \\
\hline & $0.5 \mathrm{M} \mathrm{H}_{2} \mathrm{SO}_{4}$ & 81 & 41.6 & \\
\hline $\mathrm{NiCoP} / \mathrm{rGO}^{3}$ & $0.5 \mathrm{M} \mathrm{H}_{2} \mathrm{SO}_{4}$ & 58 & 50.0 & [46] \\
\hline V-Ni2P NSAs/CC ${ }^{4,5}$ & $1.0 \mathrm{M} \mathrm{KOH}$ & 85 & 95.0 & [47] \\
\hline $\mathrm{Ni}_{0.82} \mathrm{Co}_{0.18} \mathrm{O} @ \mathrm{C} / \mathrm{NF}^{6}$ & $1.0 \mathrm{M} \mathrm{KOH}$ & 102 & 139.0 & [48] \\
\hline $\mathrm{Fe}_{11 \%}-\mathrm{NiO} / \mathrm{NF}$ & $1.0 \mathrm{M} \mathrm{KOH}$ & 88 & 49.7 & [49] \\
\hline $\mathrm{Ni}(\mathrm{Cu}) \mathrm{VO}_{x}$ & $1.0 \mathrm{M} \mathrm{KOH}$ & 21 & 28 & [50] \\
\hline $\mathrm{NiP}_{1.93} \mathrm{Se}_{0.07}$ & $0.5 \mathrm{M} \mathrm{H}_{2} \mathrm{SO}_{4}$ & 84 & 41.0 & [20] \\
\hline $\mathrm{Ni}\left(\mathrm{S}_{0.61} \mathrm{Se}_{0.39}\right)_{2}$ & $1.0 \mathrm{M} \mathrm{KOH}$ & 62.7 & 62.0 & [51] \\
\hline b-S-Ni ${ }_{3} \mathrm{Se}_{4} \& \mathrm{~b}-\mathrm{Se}-\mathrm{Ni}_{3} \mathrm{~S}_{2} / \mathrm{NF}^{7}$ & $1.0 \mathrm{M} \mathrm{KOH}$ & 87 & 61.0 & [52] \\
\hline $\mathrm{C}-\mathrm{Ni}_{1-\mathrm{X}} \mathrm{O}$ & $1.0 \mathrm{M} \mathrm{KOH}$ & 27 & 36.0 & [53] \\
\hline $\mathrm{C}, \mathrm{N}-\mathrm{NiPS}_{3}$ & $1.0 \mathrm{M} \mathrm{KOH}$ & 53.2 & 38.2 & [54] \\
\hline
\end{tabular}

1 TM, Ti mesh; ${ }^{2} \mathrm{NF}, \mathrm{Ni}$ foam; ${ }^{3} \mathrm{rGO}$, reduced graphene oxide; ${ }^{4} \mathrm{NSAs}$, nanosheet arrays; ${ }^{5} \mathrm{CC}$, carbon cloth;

${ }^{6} \mathrm{C}$, conductive carbon; ${ }^{7} \mathrm{~b}$, bulk. 


\subsection{Non-Precious Metal Doping}

Nanostructured $\mathrm{Ni}_{2} \mathrm{P}$ is an active HER electrocatalyst composed of the cheap and abundant earth elements $\mathrm{Ni}$ and $\mathrm{P}$. In order to further improve its catalytic activity, various metal dopants have been developed [55]. Zhang et al., synthesized a Mn-doped $\mathrm{Ni}_{2} \mathrm{P}$ nanosheet array $\left(\mathrm{Mn}_{0.05} \mathrm{Ni}_{0.95} \mathrm{P}_{0.52}\right)$ on nickel foam (NF) by a hydrothermal and a subsequent low-temperature phosphorization method for efficient HER electrocatalysis [56]. XPS results revealed the Mn ions were in +2 valence state. The $\mathrm{Mn}-\mathrm{Ni}_{2} \mathrm{P} / \mathrm{NF}$ only required a low overpotential of $103 \mathrm{mV}$ to drive a $\mathrm{H}_{2}$-evolving current density of $20 \mathrm{~mA} / \mathrm{cm}^{2}$ in $1.0 \mathrm{M} \mathrm{KOH}$, which was $82 \mathrm{mV}$ lower than the $\mathrm{Ni}_{2} \mathrm{P} / \mathrm{NF}$. The doping of $\mathrm{Mn}$ not only improved the electron transfer rate of $\mathrm{Ni}_{2} \mathrm{P}$ but also increased its surface area and therefore resulted in more active sites exposed, thus greatly enhancing the HER activity of the catalyst.

Wang et al., reported a Mo-doped hollow nanostructure $\mathrm{Ni}_{2} \mathrm{P}\left(\mathrm{Mo}-\mathrm{Ni}_{2} \mathrm{P}\right)$ that prepared by solvothermal and in-situ phosphorization method. The Mo-doped $\mathrm{Ni}_{2} \mathrm{P}$ (with a Mo mass ratio of $8.3 \%$ ) showed an overpotential of only $81 \mathrm{mV}$ at a $\mathrm{H}_{2}$-evolving current density of $10 \mathrm{~mA} / \mathrm{cm}^{2}$ in $1.0 \mathrm{M}$ $\mathrm{KOH}$ electrolyte (Figure 4A) [44]. First-principles DFT was employed to investigate into the Gibbs free energy of hydrogen adsorption. The Perdew-Burke-Ernzerhof (PBE) functional of generalized gradient approximation (GGA) was used as the electron exchange-correlation potential. Four types of relatively stable sites were also taken into consideration. The researchers found that in pristine $\mathrm{Ni}_{2} \mathrm{P}, \mathrm{P}$ atoms served as the active sites for HER because the $\Delta \mathrm{G}_{\mathrm{H}^{*}}$ of the $\mathrm{P}$ site in $\mathrm{Ni}_{2} \mathrm{P}$ was $\sim 0.33 \mathrm{eV}$, smaller than that of the Ni-Ni site. After Mo was doped, the $\Delta \mathrm{G}_{\mathrm{H}^{*}}$ of the P site was reduced to $0.25 \mathrm{eV}$. Moreover, Mo-Ni sites with a lower $\Delta \mathrm{G}_{\mathrm{H}^{*}}$ of $\sim 0.21 \mathrm{eV}$ appeared, which functioned as the new active centers for HER. This result indicates that proper atom doping can introduce new active centers, enlarge electrochemical active surface areas, and optimize the $\Delta \mathrm{G}_{\mathrm{H}^{*}}$ at the active sites; thereby, improving the overall HER performance of the catalyst (Figure 4B).



Figure 4. (A) Schematic illustration of the synthesis of Mo-doped $\mathrm{Ni}_{2} \mathrm{P}$ hollow nanostructures. (B) Free energy diagram for HER on Ni-Ni site in $\mathrm{Ni}_{2} \mathrm{P}, \mathrm{P}$ site in $\mathrm{Ni}_{2} \mathrm{P}, \mathrm{Mo}-\mathrm{Ni}$ site in $\mathrm{Mo}-\mathrm{Ni}_{2} \mathrm{P}$ and $\mathrm{P}$ site in

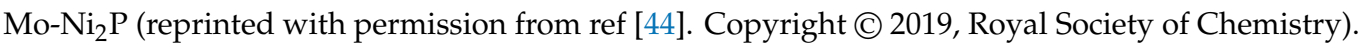

Zhang et al., reported the fabrication of single crystalline $\left(\mathrm{Fe}_{\mathrm{x}} \mathrm{Ni}_{1-\mathrm{x}}\right)_{2} \mathrm{P}$ nanosheets on $\mathrm{Ni}$ foam by hydrothermal method and a subsequent low-temperature phosphorization strategy [45]. Notably, the $\left(\mathrm{Fe}_{0.048} \mathrm{Ni}_{0.952}\right)_{2} \mathrm{P}$ catalyst showed excellent performance for HER at universal $\mathrm{pH}$ values. Through first-principle-based DFT calculations, it was found that Fe dopants can trigger the charge 
accumulation around the $\mathrm{P}$ active site, which decreased the Gibbs free energy of $\mathrm{H}^{*}$ and $\mathrm{H}_{2} \mathrm{O}$ adsorption and therefore reduced the energy barrier for $\mathrm{H}_{2}$ evolution (Figure 5). In addition, due to the Fe dopants, the accumulated charge at the $P$ sites tended to transfer to the hydrogen atom, which also benefited $\mathrm{H}_{2}$ formation. Fe dopants also enlarged the electrochemical active surface area of the catalyst, contributing to the enhanced HER performance.
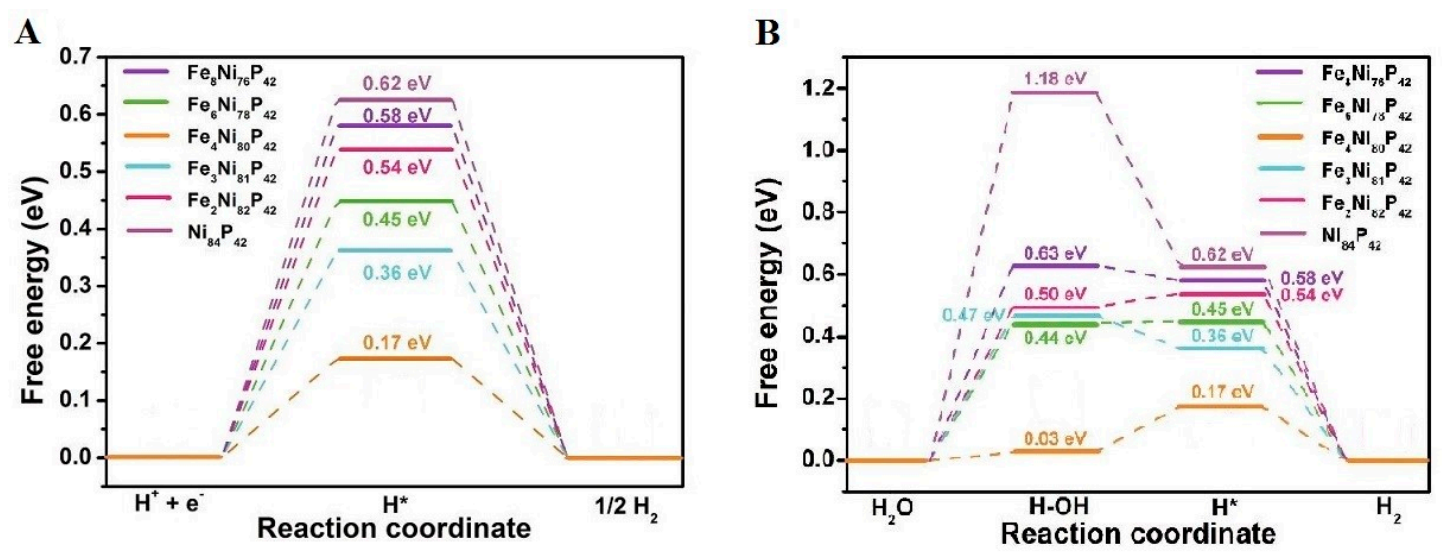

Figure 5. (A) Hydrogen adsorption free energy of $\mathrm{Fe}_{8} \mathrm{Ni}_{76} \mathrm{P}_{42}, \mathrm{Fe}_{6} \mathrm{Ni}_{78} \mathrm{P}_{42}, \mathrm{Fe}_{4} \mathrm{Ni}_{80} \mathrm{P}_{42}, \mathrm{Fe}_{3} \mathrm{Ni}_{81} \mathrm{P}_{42}$, $\mathrm{Fe}_{2} \mathrm{Ni}_{82} \mathrm{P}_{42}$, and $\mathrm{Ni}_{84} \mathrm{P}_{42}$ in acidic HER with their P sites. (B) Water dissociation energy and hydrogen adsorption free energy of $\mathrm{Fe}_{8} \mathrm{Ni}_{76} \mathrm{P}_{42}, \mathrm{Fe}_{6} \mathrm{Ni}_{78} \mathrm{P}_{42}, \mathrm{Fe}_{4} \mathrm{Ni}_{80} \mathrm{P}_{42}, \mathrm{Fe}_{3} \mathrm{Ni}_{81} \mathrm{P}_{42}, \mathrm{Fe}_{2} \mathrm{Ni}_{82} \mathrm{P}_{42}$, and $\mathrm{Ni}_{84} \mathrm{P}_{42}$ in alkaline HER with their P sites (reprinted with permission from ref [45]. Copyright (C) 2019, Elsevier).

Li et al., developed a series of Co-doped nickel phosphide catalysts $\left(\mathrm{Ni}_{2-x} \mathrm{Co}_{x} \mathrm{P}\right)$ and their hybrids with reduced graphene oxide ( $\mathrm{rGO}$ ) by co-precipitation and a subsequent phosphorization method, which exhibited excellent HER performances at universal $\mathrm{pH}$ values between 0 and 14 [46]. The HER activity of the $\mathrm{Ni}_{2-x} \mathrm{Co}_{x} \mathrm{P}$ catalyst was found relying on the ratio of $\mathrm{Ni}$ and $\mathrm{Co}$, and a $\mathrm{Ni}$ : $\mathrm{Co}$ atomic ratio of 1:1 delivered the best HER activity. Moreover, the hybridization of $\mathrm{rGO}$ onto $\mathrm{Ni}_{2-x} \mathrm{Co}_{x} \mathrm{P}$ could further improve the HER activity of the catalyst. As a result, the $\mathrm{NiCoP} / \mathrm{rGO}$ showed a small overpotential of only $55 \mathrm{mV}$ to drive a $\mathrm{H}_{2}$-evolving current density of $20 \mathrm{~mA} / \mathrm{cm}^{2}$ in acid media, as well as a low Tafel slope of $45.2 \mathrm{mV} / \mathrm{dec}$. DFT calculations showed that the presence of Co dopants in $\mathrm{NiCoP}$ not only optimized the adsorption of $\mathrm{H}$ intermediates but also accelerated the desorption of $\mathrm{H}_{2}$ at a high surface coverage of $\mathrm{H}$, contributing to the superior HER activity of the catalyst. In addition, the introduction of rGO increased the amount of the exposed actives sites and accelerated the charge transfer rate, which also conduced to the enhanced HER performance of $\mathrm{NiCoP} / \mathrm{rGO}$.

Wen et al., fabricated an 8 at $\%$ V-doped $\mathrm{Ni}_{2} \mathrm{P}$ nanosheet arrays on carbon cloth (CC) substrate

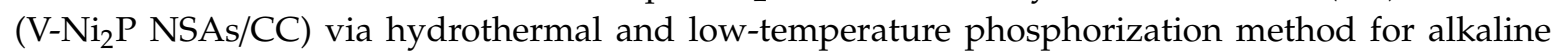
HER [47]. XPS results revealed that after doping with $V$, the binding energies of Ni shifted to lower values, indicating a higher electron density on the $\mathrm{Ni}$. It was proposed that the interaction between the vanadium and nickel atoms would cause lattice defects and distortions to $\mathrm{Ni}_{2} \mathrm{P}$; thereby, adjusting its electronic structure and increasing its specific reactive surface area (Figure 6). In addition, the in

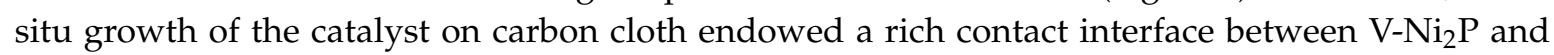
$\mathrm{CC}$; therefore, facilitating their charge carrier migration rate. IN addition, the porous structure and rough surface of $\mathrm{V}-\mathrm{Ni}_{2} \mathrm{P} / \mathrm{CC}$ could promote the release of $\mathrm{H}_{2}$ bubbles; hence, accelerating the HER process. Therefore, the $\mathrm{V}-\mathrm{Ni}_{2} \mathrm{P}$ NSAs/CC catalyst exhibited superior HER performance, with a low overpotential of $85 \mathrm{mV}$ at a current density of $10 \mathrm{~mA} / \mathrm{cm}^{2}$ in $1.0 \mathrm{M} \mathrm{KOH}$ and also an impressive long-term electrochemical stability. 



Figure 6. (A) Schematic illustration of synthesis of the V-Ni ${ }_{2} \mathrm{P}$ NSAs loaded on carbon cloth. (B) SEM images of $\mathrm{V}-\mathrm{Ni}_{2} \mathrm{P}$ NSAs/CC. (C) Polarization curves of bare CC, $\mathrm{Ni}_{2} \mathrm{P}$ NSAs/CC, $\mathrm{V}-\mathrm{Ni}_{2} \mathrm{P}$ NSAs/CC and $\mathrm{Pt} / \mathrm{C}$ (reprinted with permission from ref [47]. Copyright (C) 2019, Royal Society of Chemistry).

Apart from $\mathrm{Ni}_{2} \mathrm{P}$, researchers have also been employing non-precious metal doping to improve the HER performance of $\mathrm{NiO}$ catalyst [48]. Like most transition metal oxide-based catalysts, NiO shows good activity for oxygen evolution reaction (OER), however, its catalytic activity for HER is not satisfactory [57]. Yang et al., fabricated a Co-doped NiO coupling with conductive carbon on nickel foam $\left(\mathrm{Ni}_{0.82} \mathrm{Co}_{0.18} \mathrm{O} @ \mathrm{C} / \mathrm{NF}\right)$ for overall water splitting catalysis via an immersion-adsorption-pyrolysis method [48]. Owning to the increased conductivity, accelerated charge transfer rate, additional defect active sites, increased exposed reactive surface area and enhanced mass transfer capability, this catalyst exhibited an only $62 \mathrm{mV}$ overpotential at a $\mathrm{H}_{2}$-evolving current density of $10 \mathrm{~mA} / \mathrm{cm}^{2}$ in $1.0 \mathrm{M} \mathrm{KOH}$. It is also worth noting that the catalyst only required an ultra-low battery voltage of $1.42 \mathrm{~V}$ for overall water splitting at $10 \mathrm{~mA} / \mathrm{cm}^{2}$. Wu et al. incorporated a different transition metal, $\mathrm{Fe}$, to fabricate Fe-doped $\mathrm{NiO}$ mesoporous nanosheet arrays on nickel foam $\left(\mathrm{Fe}_{11} \%-\mathrm{NiO} / \mathrm{NF}, 11 \%\right.$ : atomic content of Fe dopants) by a solvothermal and subsequent annealing strategy [49]. Their results revealed that $\mathrm{Fe}^{3+}$ ions could induce a partial-charge-transfer process that activated the $\mathrm{Ni}^{2+}$ centers of $\mathrm{NiO}$, which effectively promoted the HER catalytic performance. Hence, the optimized $\mathrm{Fe}_{11 \%}-\mathrm{NiO} / \mathrm{NF}$ catalyst showed an overpotential of $88 \mathrm{mV}$ at a $\mathrm{H}_{2}$-evolving current density of $10 \mathrm{~mA} / \mathrm{cm}^{2}$ and a small Tafel slope of $49.7 \mathrm{mV} / \mathrm{dec}$ in $1.0 \mathrm{M} \mathrm{KOH}$ (Figure 7).

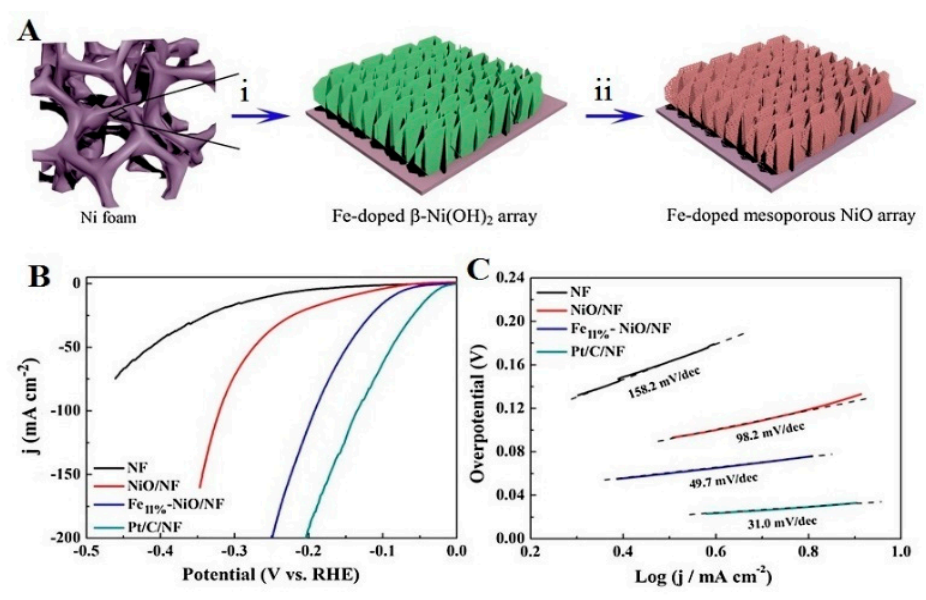

Figure 7. (A) Schematic illustration of the formation of Fe-doped mesoporous $\mathrm{NiO}$ on $\mathrm{Ni}$ foam. (i) Solvothermal synthesis of Fe-doped $\beta-\mathrm{Ni}(\mathrm{OH})_{2}$ and (ii) the calcination of Fe-doped $\beta-\mathrm{Ni}(\mathrm{OH})_{2}$ in air to produce Fe-doped mesoporous $\mathrm{NiO}$ array. (B) Polarization curves of NF (nickel foam), NiO/NF, $\mathrm{Fe}_{11} \%-\mathrm{NiO} / \mathrm{NF}$ and $\mathrm{Pt} / \mathrm{C} / \mathrm{NF}$. (C) Tafel slopes of NF, NiO/NF, $\mathrm{Fe}_{11 \%}-\mathrm{NiO} / \mathrm{NF}$ and $\mathrm{Pt} / \mathrm{C} / \mathrm{NF}$ (reprinted with permission from ref [49]. Copyright (C) 2018, Elsevier). 
$\mathrm{Ni}$, as a non-noble metal catalyst, shows poor HER performance due to its inherent electronic structure. $\mathrm{Li}$ et al., fabricated a $\mathrm{Ni}(\mathrm{Cu}) \mathrm{VO}_{x}$ catalyst with highly active $\mathrm{Ni}-\mathrm{O}-\mathrm{VO}_{x}$ sites by doping $\mathrm{VO}_{x}$ into $\mathrm{Cu}$-doped $\mathrm{Ni}$ via a one-step electrodeposition method [50]. XPS revealed that $\mathrm{Cu}$ dopants were in metallic state while the $\mathrm{V}$ existed as $\mathrm{VO}_{x}$ with low vanadium oxide valence states of +4 and +5 . The molar ratios of $\mathrm{Cu} / \mathrm{Ni}$ and $\mathrm{V} / \mathrm{Ni}$ were measured to be $\sim 0.120$ and $\sim 0.034$, respectively. This $\mathrm{Ni}(\mathrm{Cu}) \mathrm{VO}_{x}$ displayed excellent HER performance, with an overpotential as low as $21 \mathrm{mV}$ at $10 \mathrm{~mA} / \mathrm{cm}^{2}$ and a small Tafel slope of $28 \mathrm{mV} / \mathrm{dec}$ in $1 \mathrm{M} \mathrm{KOH}$ (Figure $8 \mathrm{~A}, \mathrm{~B}$ ). The spin-polarized DFT calculations indicated the excellent performance was attributed to the synergistic effects generated by the $\mathrm{VO}_{x}$ and $\mathrm{Cu}$ dopants. The incorporation of $\mathrm{VO}_{x}$ into $\mathrm{Ni}(\mathrm{Cu}) \mathrm{VO}_{x}$ would induce partial electron transfer from the $\mathrm{Ni}$ to $\mathrm{VO}_{x}$ to form super-active $\mathrm{Ni}-\mathrm{O}-\mathrm{VO}_{x}$ sites while the $\mathrm{Cu}$ dopants could further weaken the $\mathrm{H}^{*}$ binding; hence, promoting the HER performance (Figure $8 \mathrm{C}$ ). In addition, $\mathrm{Cu}$ and $\mathrm{VO}_{x}$ doping enlarged the electrochemically reactive area of the catalyst, which also contributed to the enhanced HER performance of the $\mathrm{Ni}(\mathrm{Cu}) \mathrm{VO}_{x}$ (Figure $8 \mathrm{D}$ ).
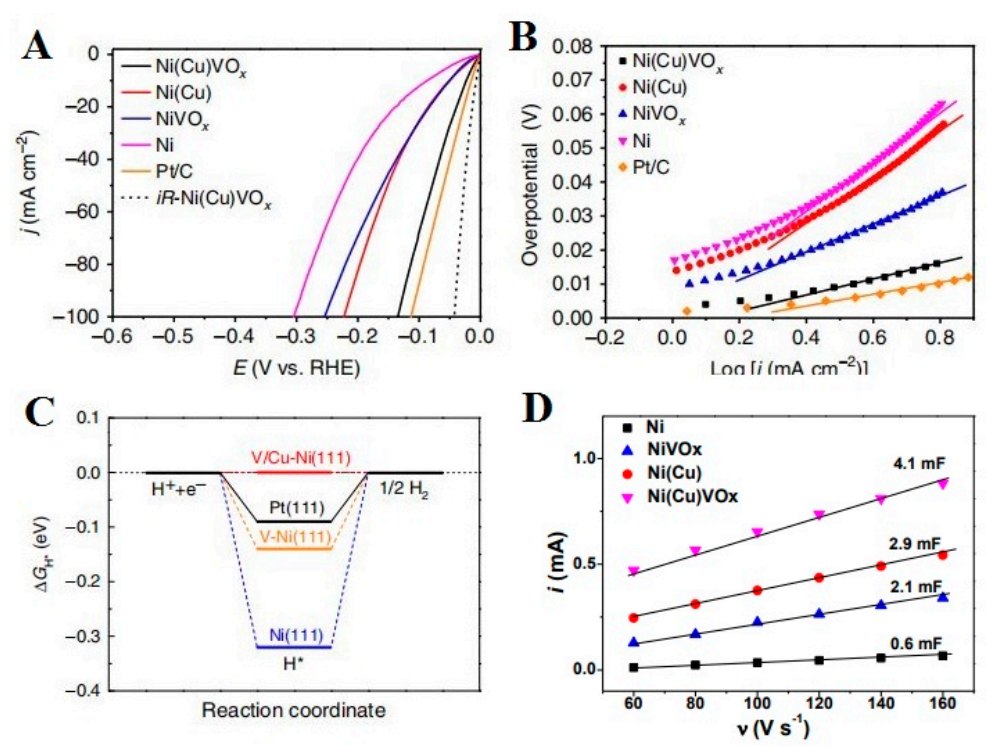

Figure 8. (A) Polarization curves of $\mathrm{Ni}, \mathrm{Ni}(\mathrm{Cu}), \mathrm{NiVO}_{x}, \mathrm{Ni}(\mathrm{Cu}) \mathrm{VO}_{x}, i R-\mathrm{Ni}(\mathrm{Cu}) \mathrm{VO}_{x}$ and $\mathrm{Pt} / \mathrm{C}$. (B) Tafel plots of $\mathrm{Ni}, \mathrm{Ni}(\mathrm{Cu}), \mathrm{NiVO}_{x}, \mathrm{Ni}(\mathrm{Cu}) \mathrm{VO}_{x}$, and $\mathrm{Pt} / \mathrm{C}$. (C) The calculated $\Delta \mathrm{G}_{\mathrm{H}^{*}}$ of $\mathrm{Ni}(111), \mathrm{V}-\mathrm{Ni}(111)$, $\mathrm{Pt}(111)$, and $\mathrm{V} / \mathrm{Cu}-\mathrm{Ni}(111)$. (D) Double-layer capacitances of $\mathrm{Ni}, \mathrm{Ni}(\mathrm{Cu}), \mathrm{NiVO}_{x}$, and $\mathrm{Ni}(\mathrm{Cu}) \mathrm{VO}_{x}$ calculated from their CVs at different scan rates (reprinted with permission from ref [50]. Copyright (C) 2020, Springer).

\subsection{Non-Metal Doping}

Studies have shown that doping anions from a different group into an existing catalyst is an effective strategy to improve the HER performance [58-60]. Zhuo et al., systematically investigated a series of pyrite-phase nickel selenide and phosphide materials that prepared via a hydrothermal and subsequent thermal conversion method. Among samples with various $\mathrm{P} / \mathrm{Se}$ ratios, Se-doped $\mathrm{NiP}_{2}$ $\left(\mathrm{NiP}_{1.93} \mathrm{Se}_{0.07}\right)$ showed the best HER performance, with an overpotential as low as $84 \mathrm{mV}$ at $10 \mathrm{~mA} / \mathrm{cm}^{2}$ and a small Tafel slope of $41 \mathrm{mV} / \mathrm{dec}$ in $0.5 \mathrm{M} \mathrm{H}_{2} \mathrm{SO}_{4}$ aqueous electrolyte [20]. The performance improvement of $\mathrm{NiP}_{2}$ was proposed to be attributed to the introduction of Se elements, which modified the electronic structure of $\mathrm{NiP}_{2}$. The changes in the electronic structure further optimized the free energy of hydrogen adsorption on the catalyst and therefore improved the HER activity of $\mathrm{NiP}_{2}$ catalyst.

A different work by Zhou et al. also revealed the importance of anion doping in enhancing the activity of water splitting catalyst [51]. The researchers investigated into the anion doping effect in pyrite-structured nickel disulfide $\left(\mathrm{NiS}_{2}\right)$ or nickel diselenide $\left(\mathrm{NiSe}_{2}\right)$ that prepared via a solvothermal and subsequent calcination and chemical vapor deposition strategy. The authors found 
that $\mathrm{Ni}\left(\mathrm{S}_{0.61} \mathrm{Se}_{0.39}\right)_{2}$ had a remarkable HER activity with an overpotential of only $62.7 \mathrm{mV}$ at a current density of $10 \mathrm{~mA} / \mathrm{cm}^{2}$ in $1 \mathrm{M} \mathrm{KOH}$. The XPS results revealed that Se doping in $\mathrm{NiS}_{2}$, due to the smaller electronegativity of Se compared to S, led to a decrease in the valence of Ni. Further DFT calculations, which employed the Perdew-Burke-Erzenhof exchange and correlation functional with Hubbard U correction $(\mathrm{PBE}+\mathrm{U})$, revealed that appropriate anion doping regulated the d-band center of the catalyst, which led to a neither too strong nor too weak binding strength of $\mathrm{H}^{*}$-catalyst, therefore enhancing its intrinsic HER activity.

Liu et al., utilized a hydrothermal strategy to synthesize the bulk S-doped $\mathrm{Ni}_{3} \mathrm{Se}_{4}$ and the bulk Se-doped $\mathrm{Ni}_{3} \mathrm{~S}_{2}$ hybrid catalyst (b-S-Ni $\mathrm{Ni}_{3} \mathrm{Se}_{4} \& \mathrm{~b}-\mathrm{Se}-\mathrm{Ni}_{3} \mathrm{~S}_{2}$, atomic contents of $\mathrm{Se}, \mathrm{S}$, and Ni: $30.7 \%, 18.5 \%$ and $50.8 \%$, respectively) for HER [52]. Through DFT calculations, it was found that dopants in and beneath the nickel chalcogenide catalyst surface would both contribute to the HER performance. Compared to surface-only doping, bulk doping can optimize the $\Delta \mathrm{G}_{\mathrm{H}^{*}}$ of the S-doped $\mathrm{Ni}_{3} \mathrm{Se}_{4}$ and the Se-doped $\mathrm{Ni}_{3} \mathrm{~S}_{2}$; hence, promoting the intrinsic activity of the catalyst. In addition, b-S-Ni $\mathrm{Si}_{3} \& \mathrm{~b}-\mathrm{Se}-\mathrm{Ni}_{3} \mathrm{~S}_{2}$ showed a porous structure and had a large electrochemical active surface area, which also contributed to the enhanced HER performance of the catalyst. As a result, the b-S-Ni $\mathrm{Ni}_{3} \mathrm{Se}_{4} \& \mathrm{~b}-\mathrm{Se}-\mathrm{Ni}_{3} \mathrm{~S}_{2}$ exhibited a low overpotential of $87 \mathrm{mV}$ at a $\mathrm{H}_{2}$-evolving current density of $10 \mathrm{~mA} / \mathrm{cm}^{2}$ in $1.0 \mathrm{M} \mathrm{KOH}$ electrolyte.

Kou et al., through an anodization and subsequent annealing treatment, successfully doped carbon into $\mathrm{NiO}$ to activate the catalyst for alkali HER catalysis [53]. Carbon doping caused distortions to the $\mathrm{NiO}$ local structure because the coordination number and radius of carbon did not match with the Ni. As a result, the coordination number of top-layer Ni decreased from 6 to 3 with $\mathrm{C}$ doping (Figure 9A). This change led to an increase in the charge density of the Ni sites, making Ni more favorable for $\mathrm{H}^{*}$ adsorption. In addition, DFT calculations $(\mathrm{PBE}+\mathrm{U})$ revealed that carbon dopants facilitated the dissociation of $\mathrm{H}_{2} \mathrm{O}$ molecules based on its low energy barrier of $0.81 \mathrm{eV}$, while without carbon dopants, the energy barrier was as high as $1.17 \mathrm{eV}$. Therefore, the $1.83 \mathrm{at} \%$ carbon-doped $\mathrm{Ni}_{1-\mathrm{x}} \mathrm{O}$ exhibited excellent HER performance, with only $27 \mathrm{mV}$ overpotential at a $\mathrm{H}_{2}$-evolving current density of $10 \mathrm{~mA} / \mathrm{cm}^{2}$ and a small Tafel slope of only $36 \mathrm{mV} / \mathrm{dec}$ in $1.0 \mathrm{M} \mathrm{KOH}$ aqueous electrolyte (Figure 9B,C).

A

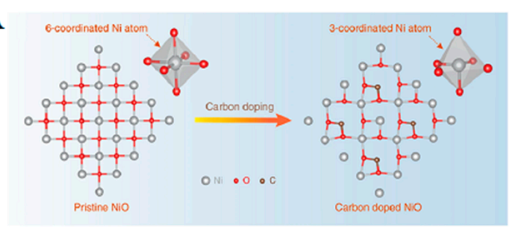

C

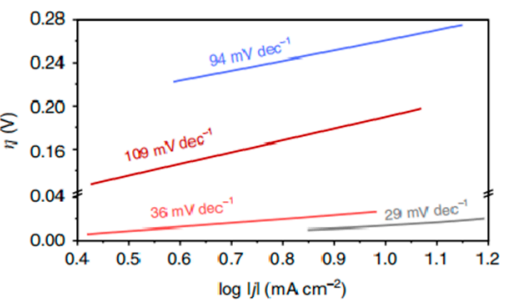

B



Figure 9. (A) Density functional theory (DFT) calculations for the structure changes of NiO with carbon doping. (B) Polarization curves of $\mathrm{NF}, \mathrm{C}-\mathrm{Ni}_{1-x} \mathrm{O}-\mathrm{Air}$ (annealed in air), $\mathrm{C}-\mathrm{Ni}_{1-\mathrm{x}} \mathrm{O}$, and $\mathrm{Pt} / \mathrm{C}$ in $\mathrm{N}_{2}$-saturated 1.0 M KOH. (C) Tafel slopes of $\mathrm{NF}, \mathrm{C}-\mathrm{Ni}_{1-x} \mathrm{O}-\mathrm{Air}, \mathrm{C}-\mathrm{Ni}_{1-\mathrm{x}} \mathrm{O}$, and $\mathrm{Pt} / \mathrm{C}$ (reprinted with permission from ref [53]. Copyright (C) 2020, Springer).

Semiconductor-like substances, for example $\mathrm{NiPS}_{3}$, due to its semiconducting nature and inert basal plane, does not exhibit satisfactory HER performances. Wang et al. theoretically designed and successfully introduced a series of nonmetals into exfoliated $\mathrm{NiPS}_{3}$ catalyst via chemical vapor deposition method to enhance the HER activity [54]. Through DFT calculations, which employed 
GGA+U method (with $\mathrm{U}=4.5$ and $J=0.5 \mathrm{eV}$ ) to address the strong correlation effect among the partially filled Ni-3d orbitals, the authors predicted that $\mathrm{B}$ and $\mathrm{C}$ heteroatom doping into $\mathrm{NiPS}_{3}$ could decrease its bandgap via bringing about the appearance of electronic states around the Fermi level; therefore, the catalyst could transform to a metal-like material. The free energy of hydrogen adsorption on $\mathrm{NiPS}_{3}$ was also dominated by the degree that the valence band of $\mathrm{NiPS}_{3}$ was filled. Only appropriate doping with moderate filled state of valence band could contribute to the optimized $\Delta \mathrm{G}_{\mathrm{H}^{*}}$ approaching $0 \mathrm{eV}$. Thereafter, the authors experimentally synthesized a series of nonmetal-doped $\mathrm{NiPS}_{3}$ and found that the HER performances of the catalysts corroborated the theoretical predictions. The $4.271 \mathrm{wt} \%$ C-doped $\mathrm{NiPS}_{3}$, due to the moderate filled state of valence band, optimized the $\Delta \mathrm{G}_{\mathrm{H}^{*}}$ and therefore promoted the HER performance, while C $(3.989 \mathrm{wt} \%), \mathrm{N}(2.10 \mathrm{wt} \%)$ co-doped $\mathrm{NiPS}_{3}$ could even deliver a Pt-like HER performance (Figure 10).
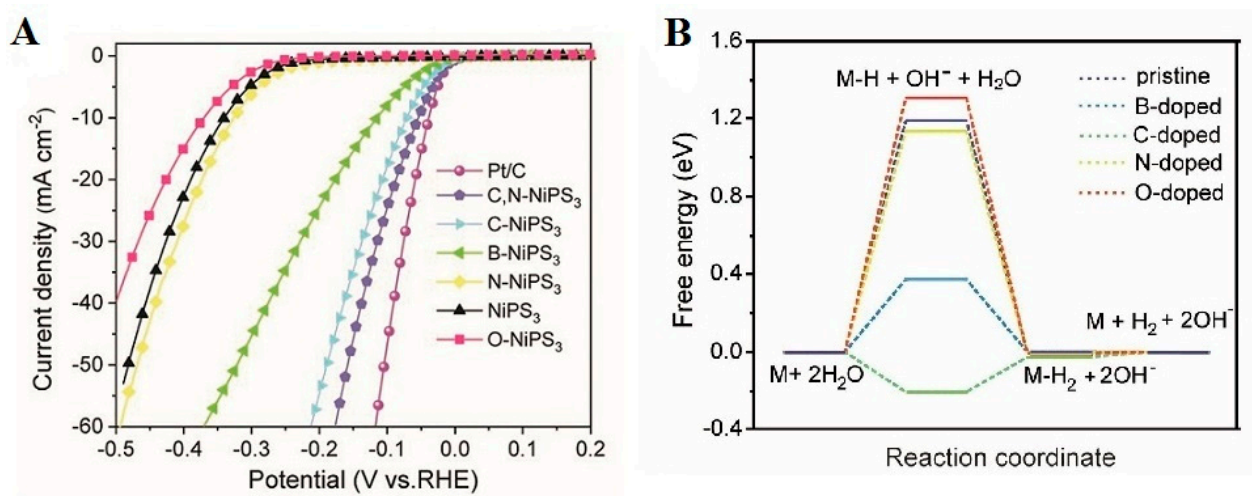

Figure 10. (A) Polarization curves of (C, N)-, C-, B-, N-, O-NiPS 3 , pristine $\mathrm{NiPS}_{3}$, and Pt/C. (B) Calculated free energies of hydrogen adsorption on different catalysts under steady-state $\mathrm{H}$ coverage by the Volmer-Heyrovsky mechanism (reprinted with permission from ref [54]. Copyright (C) 2020, John Wiley and Sons).

Yang et al., successfully incorporated $\mathrm{B}$, in the form of borate $\left(\mathrm{BO}_{3}{ }^{3-}\right)$, into NiCo $\mathrm{LDH}$ supported on $\mathrm{Ni}$ foam by dipping the solvothermally prepared $\mathrm{NiCo} \mathrm{LDH}$ in $1 \mathrm{M} \mathrm{NaBH}_{4}$ solution for $24 \mathrm{~h}$ at room temperature [61]. It was found that the borate ions partially replaced the lattice $\mathrm{OH}^{-}$in crystalline NiCo LDH, resulting in the transformation from crystalline to amorphous structure of the catalyst. The amorphorization of NiCo LDH introduced rich oxygen vacancies and unsaturated atoms, which were proposed to work as the new reactive sites for HER. In addition, the introduced oxygen vacancies also increased the conductivity of the catalyst, enabling enhanced charge transfer ability. As a result, this B-doping induced amorphous NiCo LDH on Ni foam (A-NiCo LDH/NF) demonstrated excellent HER performance that small overpotentials of only 286 and $381 \mathrm{mV}$ were required to drive the $\mathrm{H}_{2}$ evolution at 500 and $1000 \mathrm{~mA} / \mathrm{cm}^{2}$, respectively.

\section{Summary and Outlook}

During the past years, continuous efforts have been made in improving the HER performances of nickel-based electrocatalysts so as to achieve promising substitutes for Pt-based materials. Among various developed methods, elemental doping can be used to improve HER performance of Ni-based materials because appropriate doping can increase the charge transfer rate, adjust the free energy of hydrogen adsorption, and introduce new active centers to the catalysts. For example, incorporation of $\mathrm{Ru}$ dopants into $\mathrm{Ni}(\mathrm{OH})_{2}$ accelerated the charge transfer rate, and Ru dopants also functioned as the new active centers for $\mathrm{H}$ adsorption and the following $\mathrm{H}_{2}$ formation [40]. As for $\mathrm{NiP}_{2}$, Se dopants could optimize the adsorption energy of hydrogen intermediates, and therefore improved the HER performance [20]. 
Considering the recent remarkable progress made by researchers in doped Ni-based HER catalysts, we would like to highlight the following points, which we suppose not only suitable for Ni-based materials, but also applicable to other transition metal-based catalysts.

1. Single- vs. double-doping mode. As mentioned before, heteroatom doping can affect its free energies of $\mathrm{H}^{*}$ adsorption and $\mathrm{H}_{2}$ release on Ni metal [50]. However, most heteroatom doping is in single-doping mode, and its ability to adjust the electronic structure might still be limited. Instead, the double-doping mode can trigger synergistic effect and can fine-tune the electronic structure of the catalyst rather than too strongly or too weakly; thereby, improving the HER performance. Hence it is desirable that more efforts could be made in the judicious selection of different doping modes so as to achieve an optimization of the HER catalysts.

2. Single atom doping. As mentioned above, the introduction of single-atom Ru into $\mathrm{Ni}_{5} \mathrm{P}_{4}$ would cause localized structure polarization and then create electron-rich Ru sites, reducing the energy barriers of hydrolytic ionization [41]. In addition, the localized interstitial structures would optimize the hydrogen adsorption energy; thereby, enhancing the HER performance of the $\mathrm{Ni}_{5} \mathrm{P}_{4}$ - $\mathrm{Ru}$ catalyst. Hence, we highlight single-atom doping as a strategy worthy of reference for promoting catalyst performances. Notably, single-atom doping is still of great difficulty because with smaller particle size, the free energy of metals increases significantly and therefore aggregation will occur. However, the judicious selection of an appropriate substrate that provides strong interactions with the metal species can stabilize the metal centers and significantly prevent this aggregation (e.g., $\mathrm{Ni}$ vacancies in nickel hydroxides can stabilize the Ru sites); hence, single-atom doping can be achieved [41,62].

3. Making full use of DFT calculations. DFT calculations play an increasingly important role in catalysis research. Apart from using DFT as a standard tool for answering such questions like why doping heteroatoms can increase the activity of a certain catalyst, we highlight that researchers could also employ DFT calculations as a powerful technique to predict the performances of nonexistent catalysts and therefore select out those catalysts with appropriate electronic structures for further experimental investigation. For example, Wang et al. theoretically designed and introduced a series of nonmetals $\left(\mathrm{B}, \mathrm{C}, \mathrm{N}\right.$, and $\mathrm{O}$ ) into $\mathrm{NiPS}_{3}$ catalyst, and predicted that $\mathrm{B}$ and $\mathrm{C}$ dopants could transform the semiconducting basal plane to a metal-like property [53]. Their further experimental results corroborated the DFT predictions, showing that introduction of $\mathrm{B}$ or $\mathrm{C}$ dopants did successfully activate the inert basal plane and promote the conductivity of the $\mathrm{NiPS}_{3}$ catalyst, hence enhancing the HER performance.

Finally, we would like to suggest the employment of operando techniques, such as operando Raman, IR, and XAS, for the investigation into the reactive sites and HER reaction pathways of the catalysts. These operando techniques could provide insightful information about reaction mechanisms, and along with DFT calculations, a more comprehensive understanding of the catalytic process could be obtained. This understanding would further play a guiding role in the design and synthesis of more efficient catalysts.

Author Contributions: Writing-Original draft preparation, Y.D. and W.L.; writing—review and editing, Y.D., W.L., and B.X.; supervision, B.X.; project administration, B.X.; and funding acquisition, Y.D. and B.X. All authors have read and agreed to the published version of the manuscript.

Funding: This research is supported by China Postdoctoral Science Foundation (Grant No. 2019M651716), Senior Talent Foundation of Jiangsu University (Grant No. 18JDG033, 18JDG034), and Jiangsu Planned Projects for Postdoctoral Research Fund (Grant No. 2018K102C).

Acknowledgments: Yilin Deng and Bin Xu extend sincere appreciation to Jiangsu Province's Program for High-Level Innovative and Entrepreneurial Talents Introduction.

Conflicts of Interest: The authors declare no conflict of interest. 


\section{References}

1. Du, H.; Li, N.; Brown, M.A.; Peng, Y.; Shuai, Y. A bibliographic analysis of recent solar energy literatures: The expansion and evolution of a research field. Renew. Energy 2014, 66, 696-706. [CrossRef]

2. Wei, J.; Zhou, M.; Long, A.; Xue, Y.; Liao, H.; Wei, C.; Xu, Z.J. Heterostructured Electrocatalysts for Hydrogen Evolution Reaction Under Alkaline Conditions. Nano-Micro Lett. 2018, 10, 75. [CrossRef] [PubMed]

3. Turner, J.A. Sustainable hydrogen production. Science 2004, 305, 972-974. [CrossRef] [PubMed]

4. Wang, H.; Gao, L. Recent developments in electrochemical hydrogen evolution reaction. Curr. Opin. Electrochem. 2018, 7, 7-14. [CrossRef]

5. Suryanto, B.H.R.; Wang, Y.; Hocking, R.K.; Adamson, W.; Zhao, C. Overall electrochemical splitting of water at the heterogeneous interface of nickel and iron oxide. Nat. Commun. 2019, 10, 5599. [CrossRef]

6. Lei, Y.; Wang, Y.; Liu, Y.; Song, C.; Li, Q.; Wang, D.; Li, Y. Realizing the atomic active center for hydrogen evolution electrocatalysts. Angew. Chem. Int. Ed. 2020. [CrossRef]

7. Cheng, N.; Stambula, S.; Wang, D.; Banis, M.N.; Liu, J.; Riese, A.; Xiao, B.; Li, R.; Sham, T.K.; Liu, L.M.; et al. Platinum single-atom and cluster catalysis of the hydrogen evolution reaction. Nat. Commun. 2016, 7, 13638. [CrossRef]

8. Xiao, P.; Sk, M.A.; Thia, L.; Ge, X.; Lim, R.J.; Wang, J.-Y.; Lim, K.H.; Wang, X. Molybdenum phosphide as an efficient electrocatalyst for the hydrogen evolution reaction. Energy Environ. Sci. 2014, 7, 2624-2629. [CrossRef]

9. Chen, Y.; Xu, S.; Li, Y.; Jacob, R.J.; Kuang, Y.; Liu, B.; Wang, Y.; Pastel, G.; Salamanca-Riba, L.G.; Zachariah, M.R.; et al. $\mathrm{FeS}_{2}$ Nanoparticles Embedded in Reduced Graphene Oxide toward Robust, High-Performance Electrocatalysts. Adv. Energy Mater. 2017, 7, 1700482. [CrossRef]

10. Zhou, G.; Li, M.; Li, Y.; Dong, H.; Sun, D.; Liu, X.; Xu, L.; Tian, Z.; Tang, Y. Regulating the Electronic Structure of CoP Nanosheets by O Incorporation for High-Efficiency Electrochemical Overall Water Splitting. Adv. Funct. Mater. 2019, 30, 1905252. [CrossRef]

11. Lei, C.; Wang, Y.; Hou, Y.; Liu, P.; Yang, J.; Zhang, T.; Zhuang, X.; Chen, M.; Yang, B.; Lei, L.; et al. Efficient alkaline hydrogen evolution on atomically dispersed $\mathrm{Ni}-\mathrm{N}_{\mathrm{x}}$ Species anchored porous carbon with embedded $\mathrm{Ni}$ nanoparticles by accelerating water dissociation kinetics. Energy Environ. Sci. 2019, 12, 149-156. [CrossRef]

12. Gong, M.; Wang, D.-Y.; Chen, C.-C.; Hwang, B.-J.; Dai, H. A mini review on nickel-based electrocatalysts for alkaline hydrogen evolution reaction. Nano Res. 2015, 9, 28-46. [CrossRef]

13. Kong, Q.; Feng, W.; Ma, S.; Sun, F.; Xie, X.; Sun, C. Hydrothermal Synthesis of Nanoporous NiO Rods Self-Supported on Ni Foam as Efficient Electrocatalysts for Hydrogen Evolution Reaction. JOM 2018, 71, 621-625. [CrossRef]

14. Danilovic, N.; Subbaraman, R.; Strmcnik, D.; Chang, K.C.; Paulikas, A.P.; Stamenkovic, V.R.; Markovic, N.M. Enhancing the alkaline hydrogen evolution reaction activity through the bifunctionality of $\mathrm{Ni}(\mathrm{OH})_{2} / \mathrm{metal}$ catalysts. Angew. Chem. Int. Ed. 2012, 51, 12495-12498. [CrossRef]

15. Feng, L.; Vrubel, H.; Bensimon, M.; Hu, X. Easily-prepared dinickel phosphide $\left(\mathrm{Ni}_{2} \mathrm{P}\right)$ nanoparticles as an efficient and robust electrocatalyst for hydrogen evolution. Phys. Chem. Chem. Phys. 2014, 16, 5917-5921. [CrossRef]

16. Wu, X.; Yang, B.; Li, Z.; Lei, L.; Zhang, X. Synthesis of supported vertical $\mathrm{NiS}_{2}$ nanosheets for hydrogen evolution reaction in acidic and alkaline solution. RSC Adv. 2015, 5, 32976-32982. [CrossRef]

17. Ray, C.; Lee, S.C.; Jin, B.; Kundu, A.; Park, J.H.; Chan Jun, S. Conceptual design of three-dimensional $\mathrm{CoN} / \mathrm{Ni}_{3} \mathrm{~N}$-coupled nanograsses integrated on $\mathrm{N}$-doped carbon to serve as efficient and robust water splitting electrocatalysts. J. Mater. Chem. A 2018, 6, 4466-4476. [CrossRef]

18. Cao, Z.; Chen, Q.; Zhang, J.; Li, H.; Jiang, Y.; Shen, S.; Fu, G.; Lu, B.A.; Xie, Z.; Zheng, L. Platinum-nickel alloy excavated nano-multipods with hexagonal close-packed structure and superior activity towards hydrogen evolution reaction. Nat. Commun. 2017, 8, 15131. [CrossRef]

19. Shi, Y.; Zhang, B. Recent advances in transition metal phosphide nanomaterials: Synthesis and applications in hydrogen evolution reaction. Chem. Soc. Rev. 2016, 45, 1529-1541. [CrossRef]

20. Zhuo, J.; Cabán-Acevedo, M.; Liang, H.; Samad, L.; Ding, Q.; Fu, Y.; Li, M.; Jin, S. High-Performance Electrocatalysis for Hydrogen Evolution Reaction Using Se-Doped Pyrite-Phase Nickel Diphosphide Nanostructures. ACS Catal. 2015, 5, 6355-6361. [CrossRef]

21. Wu, C.; Liu, B.; Wang, J.; Su, Y.; Yan, H.; Ng, C.; Li, C.; Wei, J. 3D structured Mo-doped $\mathrm{Ni}_{3} \mathrm{~S}_{2}$ nanosheets as efficient dual-electrocatalyst for overall water splitting. Appl. Surf. Sci. 2018, 441, 1024-1033. [CrossRef] 
22. Li, S.; Xi, C.; Jin, Y.-Z.; Wu, D.; Wang, J.-Q.; Liu, T.; Wang, H.-B.; Dong, C.-K.; Liu, H.; Kulinich, S.A.; et al. Ir-O-V Catalytic Group in Ir-Doped $\mathrm{NiV}(\mathrm{OH})_{2}$ for Overall Water Splitting. ACS Energy Lett. 2019, 4, 1823-1829. [CrossRef]

23. Xiao, X.; Wu, X.; Wang, Y.; Zhu, K.; Liu, B.; Cai, X.; Yang, T.; Xu, X.; Zhang, D. Co-doped porous Ni $\mathrm{N}_{4}$ nanoflower: An efficient hydrogen evolution electrocatalyst with high activity and electrochemical stability. Catal. Commun. 2020, 138, 105957. [CrossRef]

24. Shang, X.; Zhang, X.-Y.; Xie, J.-Y.; Dong, B.; Chi, J.-Q.; Guo, B.-Y.; Yang, M.; Chai, Y.-M.; Liu, C.-G. Double-catalytic-site engineering of nickel-based electrocatalysts by group VB metals doping coupling with in-situ cathodic activation for hydrogen evolution. Appl. Catal. B 2019, 258, 117984. [CrossRef]

25. Liu, T.; Li, P.; Yao, N.; Cheng, G.; Chen, S.; Luo, W.; Yin, Y. CoP-Doped MOF-Based Electrocatalyst for pH-Universal Hydrogen Evolution Reaction. Angew. Chem. Int. Ed. 2019, 58, 4679-4684. [CrossRef]

26. Zhu, J.; Hu, L.; Zhao, P.; Lee, L.Y.S.; Wong, K.Y. Recent Advances in Electrocatalytic Hydrogen Evolution Using Nanoparticles. Chem. Rev. 2020, 120, 851-918. [CrossRef]

27. Luo, J.; Im, J.H.; Mayer, M.T.; Schreier, M.; Nazeeruddin, M.K.; Park, N.G.; Tilley, S.D.; Fan, H.J.; Gratzel, M. Water photolysis at $12.3 \%$ efficiency via perovskite photovoltaics and Earth-abundant catalysts. Science 2014, 345, 1593-1596. [CrossRef]

28. Fu, H.; Chen, Y.; Ren, Z.; Xiao, Y.; Liu, Y.; Zhang, X.; Tian, G. Highly dispersed of $\mathrm{Ni}_{0.85}$ Se nanoparticles on nitrogen-doped graphene oxide as efficient and durable electrocatalyst for hydrogen evolution reaction. Electrochim. Acta 2018, 262, 107-114. [CrossRef]

29. Vrubel, H.; Moehl, T.; Gratzel, M.; Hu, X. Revealing and accelerating slow electron transport in amorphous molybdenum sulphide particles for hydrogen evolution reaction. Chem. Commun. 2013, 49, 8985-8987. [CrossRef]

30. Zou, X.; Zhang, Y. Noble metal-free hydrogen evolution catalysts for water splitting. Chem. Soc. Rev. 2015, 44, 5148-5180. [CrossRef]

31. Wang, J.; Xu, F.; Jin, H.; Chen, Y.; Wang, Y. Non-Noble Metal-based Carbon Composites in Hydrogen Evolution Reaction: Fundamentals to Applications. Adv. Mater. 2017, 29, 1605838. [CrossRef] [PubMed]

32. Zheng, Y.; Jiao, Y.; Vasileff, A.; Qiao, S.Z. The Hydrogen Evolution Reaction in Alkaline Solution: From Theory, Single Crystal Models, to Practical Electrocatalysts. Angew. Chem. Int. Ed. 2018, 57, 7568-7579. [CrossRef] [PubMed]

33. Rui Wu, J.Z. Yanmei Shi, Dali Liu, and Bin Zhang, Metallic $\mathrm{WO}_{2}$-Carbon Mesoporous Nanowires as Highly Efficient Electrocatalysts for Hydrogen Evolution Reaction. J. Am. Chem. Soc. 2015, 137, 6983-6986.

34. Dong, Q.; Sun, C.; Dai, Z.; Zang, X.; Dong, X. Free-Standing NiO@C Nanobelt as an Efficient Catalyst for Water Splitting. Chem CatChem 2016, 8, 3484-3489. [CrossRef]

35. Rao, Y.; Wang, Y.; Ning, H.; Li, P.; Wu, M. Hydrotalcite-like Ni(OH $)_{2}$ Nanosheets in Situ Grown on Nickel Foam for Overall Water Splitting. ACS Appl. Mater. Interfaces 2016, 8, 33601-33607. [CrossRef]

36. Tang, C.; Zhang, R.; Lu, W.; Wang, Z.; Liu, D.; Hao, S.; Du, G.; Asiri, A.M.; Sun, X. Energy-Saving Electrolytic Hydrogen Generation: $\mathrm{Ni}_{2} \mathrm{P}$ Nanoarray as a High-Performance Non-Noble-Metal Electrocatalyst. Angew. Chem. Int. Ed. 2017, 56, 842-846. [CrossRef]

37. Laursen, A.B.; Patraju, K.R.; Whitaker, M.J.; Retuerto, M.; Sarkar, T.; Yao, N.; Ramanujachary, K.V.; Greenblatt, M.; Dismukes, G.C. Nanocrystalline $\mathrm{Ni}_{5} \mathrm{P}_{4}$ : A hydrogen evolution electrocatalyst of exceptional efficiency in both alkaline and acidic media. Energy Environ. Sci. 2015, 8, 1027-1034. [CrossRef]

38. Yang, C.; Gao, M.Y.; Zhang, Q.B.; Zeng, J.R.; Li, X.T.; Abbott, A.P. In-situ activation of self-supported 3D hierarchically porous $\mathrm{Ni}_{3} \mathrm{~S}_{2}$ films grown on nanoporous copper as excellent $\mathrm{pH}$-universal electrocatalysts for hydrogen evolution reaction. Nano Energy 2017, 36, 85-94. [CrossRef]

39. Xie, L.; Ren, X.; Liu, Q.; Cui, G.; Ge, R.; Asiri, A.M.; Sun, X.; Zhang, Q.; Chen, L. A Ni(OH) $)_{2}-\mathrm{PtO}_{2}$ hybrid nanosheet array with ultralow Pt loading toward efficient and durable alkaline hydrogen evolution. J. Mater. Chem. A 2018, 6, 1967-1970. [CrossRef]

40. Wang, Y.; Wang, J.; Xie, T.; Zhu, Q.; Zeng, D.; Li, R.; Zhang, X.; Liu, S. Ru doping in $\mathrm{Ni}(\mathrm{OH})_{2}$ to accelerate water reduction kinetics for efficient hydrogen evolution reaction. Appl. Surf. Sci. 2019, 485, 506-512. [CrossRef]

41. He, Q.; Tian, D.; Jiang, H.; Cao, D.; Wei, S.; Liu, D.; Song, P.; Lin, Y.; Song, L. Achieving Efficient Alkaline Hydrogen Evolution Reaction over a $\mathrm{Ni}_{5} \mathrm{P}_{4}$ Catalyst Incorporating Single-Atomic Ru Sites. Adv. Mater. 2020, 32, 1906972. [CrossRef] [PubMed] 
42. Chen, D.; Lu, R.; Pu, Z.; Zhu, J.; Li, H.-W.; Liu, F.; Hu, S.; Luo, X.; Wu, J.; Zhao, Y.; et al. Ru-doped 3D flower-like bimetallic phosphide with a climbing effect on overall water splitting. Appl. Catal. B 2020, 279, 119396. [CrossRef]

43. Fan, R.; Mu, Q.; Wei, Z.; Peng, Y.; Shen, M. Atomic Ir-doped NiCo layered double hydroxide as a bifunctional electrocatalyst for highly efficient and durable water splitting. J. Mater. Chem. A 2020, 8, 9871-9881. [CrossRef]

44. Wang, Q.; Zhao, H.; Li, F.; She, W.; Wang, X.; Xu, L.; Jiao, H. Mo-doped Ni 2 P hollow nanostructures: Highly efficient and durable bifunctional electrocatalysts for alkaline water splitting. J. Mater. Chem. A 2019, 7 , 7636-7643. [CrossRef]

45. Zhang, W.; Zou, Y.; Liu, H.; Chen, S.; Wang, X.; Zhang, H.; She, X.; Yang, D. Single-crystalline $\left(\mathrm{Fe}_{\mathrm{X}} \mathrm{Ni}_{1-\mathrm{x}}\right)_{2} \mathrm{P}$ nanosheets with dominant facets: Efficient electrocatalysts for hydrogen evolution reaction at all $\mathrm{pH}$ values. Nano Energy 2019, 56, 813-822. [CrossRef]

46. Li, J.; Yan, M.; Zhou, X.; Huang, Z.-Q.; Xia, Z.; Chang, C.-R.; Ma, Y.; Qu, Y. Mechanistic Insights on Ternary $\mathrm{Ni}_{2-\mathrm{x}} \mathrm{Co}_{\mathrm{x}} \mathrm{P}$ for Hydrogen Evolution and Their Hybrids with Graphene as Highly Efficient and Robust Catalysts for Overall Water Splitting. Adv. Funct. Mater. 2016, 26, 6785-6796. [CrossRef]

47. Wen, L.; Yu, J.; Xing, C.; Liu, D.; Lyu, X.; Cai, W.; Li, X. Flexible vanadium-doped $\mathrm{Ni}_{2} \mathrm{P}$ nanosheet arrays grown on carbon cloth for an efficient hydrogen evolution reaction. Nanoscale 2019, 11, 4198-4203. [CrossRef]

48. Yang, H.; Chen, Z.; Hao, W.; Xu, H.; Guo, Y.; Wu, R. Catalyzing overall water splitting at an ultralow cell voltage of $1.42 \mathrm{~V}$ via coupled Co-doped $\mathrm{NiO}$ nanosheets with carbon. Appl. Catal. B 2019, 252, 214-221. [CrossRef]

49. Wu, Z.; Zou, Z.; Huang, J.; Gao, F. Fe-doped NiO mesoporous nanosheets array for highly efficient overall water splitting. J. Catal. 2018, 358, 243-252. [CrossRef]

50. Li, Y.; Tan, X.; Hocking, R.K.; Bo, X.; Ren, H.; Johannessen, B.; Smith, S.C.; Zhao, C. Implanting Ni-O-VO $x$ sites into Cu-doped $\mathrm{Ni}$ for low-overpotential alkaline hydrogen evolution. Nat. Commun. 2020, 11, 2720. [CrossRef]

51. Zhou, Y.; Wang, Y.; Zhao, H.; Su, J.; Zhang, H.; Wang, Y. Investigation of anion doping effect to boost overall water splitting. J. Catal. 2020, 381, 84-95. [CrossRef]

52. Liu, T.; Diao, P.; Lin, Z.; Wang, H. Sulfur and selenium doped nickel chalcogenides as efficient and stable electrocatalysts for hydrogen evolution reaction: The importance of the dopant atoms in and beneath the surface. Nano Energy 2020, 74, 104787. [CrossRef]

53. Kou, T.; Chen, M.; Wu, F.; Smart, T.J.; Wang, S.; Wu, Y.; Zhang, Y.; Li, S.; Lall, S.; Zhang, Z.; et al. Carbon doping switching on the hydrogen adsorption activity of $\mathrm{NiO}$ for hydrogen evolution reaction. Nat. Commun. 2020, 11, 590. [CrossRef] [PubMed]

54. Wang, J.; Li, X.; Wei, B.; Sun, R.; Yu, W.; Hoh, H.Y.; Xu, H.; Li, J.; Ge, X.; Chen, Z.; et al. Activating Basal Planes of $\mathrm{NiPS}_{3}$ for Hydrogen Evolution by Nonmetal Heteroatom Doping. Adv. Funct. Mater. 2020, 30, 1908708. [CrossRef]

55. Popczun, E.J.; McKone, J.R.; Read, C.G.; Biacchi, A.J.; Wiltrout, A.M.; Lewis, N.S.; Schaak, R.E. Nanostructured nickel phosphide as an electrocatalyst for the hydrogen evolution reaction. J. Am. Chem. Soc. 2013, 135, 9267-9270. [CrossRef]

56. Zhang, Y.; Liu, Y.; Ma, M.; Ren, X.; Liu, Z.; Du, G.; Asiri, A.M.; Sun, X. A Mn-doped Ni $2_{2}$ P nanosheet array: An efficient and durable hydrogen evolution reaction electrocatalyst in alkaline media. Chem. Commun. 2017, 53, 11048-11051. [CrossRef]

57. Zhang, T.; Wu, M.-Y.; Yan, D.-Y.; Mao, J.; Liu, H.; Hu, W.-B.; Du, X.-W.; Ling, T.; Qiao, S.-Z. Engineering oxygen vacancy on $\mathrm{NiO}$ nanorod arrays for alkaline hydrogen evolution. Nano Energy 2018, 43, 103-109. [CrossRef]

58. Zhang, X.; Meng, F.; Mao, S.; Ding, Q.; Shearer, M.J.; Faber, M.S.; Chen, J.; Hamers, R.J.; Jin, S. Amorphous $\mathrm{MoS}_{x} \mathrm{Cl}_{y}$ electrocatalyst supported by vertical graphene for efficient electrochemical and photoelectrochemical hydrogen generation. Energy Environ. Sci. 2015, 8, 862-868. [CrossRef]

59. Xu, K.; Wang, F.; Wang, Z.; Zhan, X.; Wang, Q.; Cheng, Z.; Safdar, M.; He, J. Component-Controllable $\mathrm{WS}_{2(1-\mathrm{x})} \mathrm{Se}_{2 \mathrm{x}}$ Nanotubes for Efficient Hydrogen Evolution Reaction. ACS Nano 2014, 8, 8468-8476. [CrossRef]

60. Gong, Q.; Cheng, L.; Liu, C.; Zhang, M.; Feng, Q.; Ye, H.; Zeng, M.; Xie, L.; Liu, Z.; Li, Y. Ultrathin $\mathrm{MoS}_{2(1-\mathrm{x})} \mathrm{Se}_{2 \mathrm{x}}$ Alloy Nanoflakes For Electrocatalytic Hydrogen Evolution Reaction. ACS Catal. 2015, 5, 2213-2219. [CrossRef] 
61. Yang, H.; Chen, Z.; Guo, P.; Fei, B.; Wu, R. B-doping-induced amorphization of LDH for large-current-density hydrogen evolution reaction. Appl. Catal. B 2020, 261, 118240. [CrossRef]

62. Yang, Y.; Wang, A.; Qiao, B.; Li, J.; Liu, J.; Zhang, T. Single-Atom Catalysts: A New Frontier in Heterogeneous Catalysis. Acc. Chem. Res. 2013, 46, 1740-1748. [CrossRef] [PubMed]

(C) 2020 by the authors. Licensee MDPI, Basel, Switzerland. This article is an open access article distributed under the terms and conditions of the Creative Commons Attribution (CC BY) license (http://creativecommons.org/licenses/by/4.0/). 